\title{
Reflexion
}

\section{Para Dónde Va el Ambiente, Para Dónde lo cCeva la Gente}

\author{
Rey Ariel Barbón Ardila \\ Directar general. \\ Corparación Autánoma Regional del Alto Magdalena. \\ CAM
}

ientos de veces se ha dicho, pero no sobra decirlo cientos de veces más. Colombia es un país extremadamente rico en recursos naturales renovables. Los datos, manejados por diferentes organismos dedicados a la conservación ambiental, son contundentes. Colombia, aseguran, alberga más del 10\% de on la biodiversidad mundial, gracias a la innumerable cantidad de especies de fauna y flora que existen sobre su suelo. Adicional a ello, es el primero en variedad de aves, el segundo en plantas y anfibios, el cuarto en disponibilidad de agua, el sexto en reptiles y el séptimo en mamiferos.

No obstante, es lamentable reconocer que así como es grande su riqueza, son incalculables sus problemas y preocupantes sus condiciones de pobreza. De acuerdo con un reciente estudio del Instituto de Hidrología, Meteorologia y Estudios Ambientales, Ideam, sólo por cultivos ilícitos el país ha visto afectados 2.5 millones de hectáreas de bosques, un área mayor a la que ocupan departamentos como Cundinamarca. El 75 por ciento de los páramos, por su parte, está en peligro de desaparecer, debido a que la frontera agrícola en esas zonas está creciendo por la desmedida expansión de la ganadería y los cultivos de papa y amapola.

De otro lado, la temperatura promedio ha aumentado un grado centígrado en los últimos 50 años y por ello, el 70 por ciento de los glaciares de los picos más altos, erigidos sobre las cordilleras que atraviesan el extenso territorio nacional, ha disminuido. Por si fuera poco, pese a que Colombia está entre los 10 países con mayores recursos hídricos del planeta, el 54 por ciento de sus habitantes enfrenta problemas de escasez de agua en períodos secos, en especial, porque sus fuentes hacen parte de pequeñas cuencas muy vulnerables a los cambios climáticos, favorecidos por las actividades intervencionistas, poco sostenibles, de quienes permanecen asentados en ellas.

Es, sin duda, un desalentador panorama, el cual conduce a pensar en lo que cada uno de nosotros, los huilenses, con una perspectiva colectiva, es capaz de hacer. Pareceria, a simple vista, que no hay una salida rápida y efectiva, Sin embargo, considero, sí existen alternativas que sin ser fórmulas mágicas, permitirian encontrar una solución a esta dramática situación.

\section{so Alianzas Institucionales $y$ Articulación con el sector Privado$$
\text { en }
$$

Para comenzar, es imprescindible aceptar que la iniciativa que sea emprendida en favor del medio ambiente, cualquiera que sea, debe evolucionar no bajo el compromiso de una sola entidad ni mucho menos de una sola persona: por el contrario, debe ser el fruto del esfuerzo de muchas manos, sin distingo de clase, color político, raza ni religión. Lo que se busca es formar equipos de trabajo que le apunten a tareas estratégicas, como la constitución de zonas de protección, la recuperación de áreas degradadas $y$, entre muchas otras cosas, la formulación de modelos productivos que garanticen el equilibrio ambiental y la estabilidad económica.

Es entonces cuando entran en sintonía, todos los actores del escenario regional, responsables de hacer valer la labor medioambiental como un derecho, pero 
también como una responsabilidad colectiva. En este contexto es necesario insistir en la participación de los diferentes organismos del orden público, aunque sin olvidar a aquellos que están del otro lado, es decir, a quienes conforman el sector privado. Todos ellos, en conjunto, tienen la obligación legal y moral de aportar a la materialización de este objetivo, el cual debe incluir, por obvias razones, actividades de conservación y producción que puedan ser conjugadas por el avance integral de la región.

\section{so Transformación de Sistemas Productivos}

Es importante y, más aún, urgente trabajar en campos específicos, como la transformación de los sistemas productivos, una exigencia del mundo de hoy. Los conocidos productos verdes son una respuesta a las necesidades del hombre que día a día avanza en busca de mejores alternativas, lo cual lo obliga a generar procesos cambiantes, cada vez más promisorios. Es una inevitable consecuencia del grave deterioro al que están siendo sometidos nuestros recursos, víctimas de la desmedida y permanente lucha por encontrar una estabilidad económica que muchas veces va en contra de la condición misma del ser humano.

En esta época, pese al avance de la modernidad, es fácil encontrar lugares donde son marcados los conflictos por el aprovechamiento del agua y también del suelo; son zonas, día a día más comunes, donde sus moradores han ido perdiendo todo por $e$ desaforado uso de agroquimicos y otras sustancias contaminantes, $\sin$ desconocer las demás prácticas antiecológicas, que le están quitando vida a la vida. Por ello, es más que necesario poner punto final a esta historia y redireccionar su rumbo, esta vez con una mayor conciencia, con el decidido propósito de transformar los sistemas productivos hasta ahora existentes y, así, fortalecer el cambio de tecnologías, los mecanismos de formación, el establecimiento de canales de comercialización y la organización de los usuarios.
Estos últimos, fundamentales dentro de cualquier proceso que involucre el aprovechamiento de los bienes colectivos, entre otros, los recursos naturales renovables.

\section{Apropiación de las organizaciones Comunitarias de Base $y$ Gestion Integral del Agua}

Es inevitable hablar de la participación comunitaria, la cual es vital en temas como la gestión integral del agua, un asunto que engloba aquellas acciones que tienden a garantizar la permanencia de las corrientes hídricas como fuentes de vida, lo cual corresponde no sólo a las autoridades ambientales, encargadas de conservar y controlar, sino a la misma gente que puede convertirse en arte y parte. Esto, gracias a múltiples mecanismos, entre ellos, los sistemas locales de administración del recurso hídrico, figura que permite a la población responsabilizarse de las actuaciones que tengan directa incidencia sobre el uso, pero también sobre la preservación del recurso.

Sumado a eso, debe decirse que el apoyo otorgado por las organizaciones comunitarias es fundamental en éste como en cualquier otro proceso, más aún si se tiene en cuenta que en su calidad de líderes de opinión, estas formas asociativas tienen a su alcance la posibilidad de consolidarse como multiplicadoras y promotoras de ésta, nuestra causa. Ellas, sin duda, juegan un decidido papel, porque, al igual que todos nosotros, están recibiendo beneficios directos del patrimonio natural y, paradójicamente, están padeciendo las consecuencias de su inadecuada e incontrolada explotación.

\section{so Aprovechamiento del Potencial Natural para el Desarrollo Socioeconómice}

No hay que olvidar que tanta riqueza a nuestro alcance, no sólo nos permite satisfacer las más elementales necesidades,

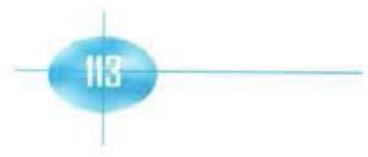


Para donde zu el ambiente, para dinde lo lleza la gente

sino que, de igual forma, constituye una oportunidad de desarrollo integral que inicia en lo ambiental, traspasa lo económico y culmina en lo social.

De ahí la importancia de aprovechar o, mejor aún, saber aprovechar todo este potencial, a través de estrategias que sin afectar la estabilidad de los recursos, se conviertan en nuevas y promisorias alternativas de vida. En este contexto encajan con precisión actividades como el ecoturismo, el cual debe ser visto como una excelente opción económica, sobre todo en momentos en los cuales, de acuerdo con la Organización Mundial del Turismo, OMT, en nuestro mundo aparentemente opulento, la pobreza sigue afectando a 4 mil millones de personas, de las que, 2 mil millones viven con menos de un dólar diario.

Es ahí donde la 'industria sin chimeneas', como ha sido denominado este renglón productivo, adquiere mayor relevancia, pues además de que nos invita a apreciar, conocer y valorar cuanto tenemos a nuestro alrededor, se consolida como una buena alternativa para acelerar el progreso económico y detener el desequilibrio ambiental.

\section{(2) Optimizaciön de la Inversión n Reducción de Gastos}

Finalmente, es prudente hablar de la reducción de los costos de funcionamiento y la optimización de los recursos destinados a inversión, manejados por aquellas entidades que legalmente tienen un compromiso con el medio ambiente. Ésta es una medida que requiere mucha disciplina y organización, pero que una vez en marcha, arroja grandes resultados y genera múltiples oportunidades.

La idea es derivar tanto provecho como sea posible del dinero que puede restarse a los gastos de operación de un estamento, destinándolo al desarrollo de estrategias que le apuesten al mejoramiento de las condiciones de vida. Es éste un mecanismo para la acertada y oportuna inversión de los recursos otorgados a la actividad ambiental, en la cual se entremezclan no uno sino diversos factores, entre ellos, las alianzas institucionales que a nivel nacional y, por qué no, internacional, logren consolidarse; la integración basada en el compromiso de la comunidad; y el aporte de los sectores públicos y privados, pues aunque parezca que es obvio y que sobra decirlo. nadie puede discutir que es más certera la fuerza, cuando es el fruto de la unión.

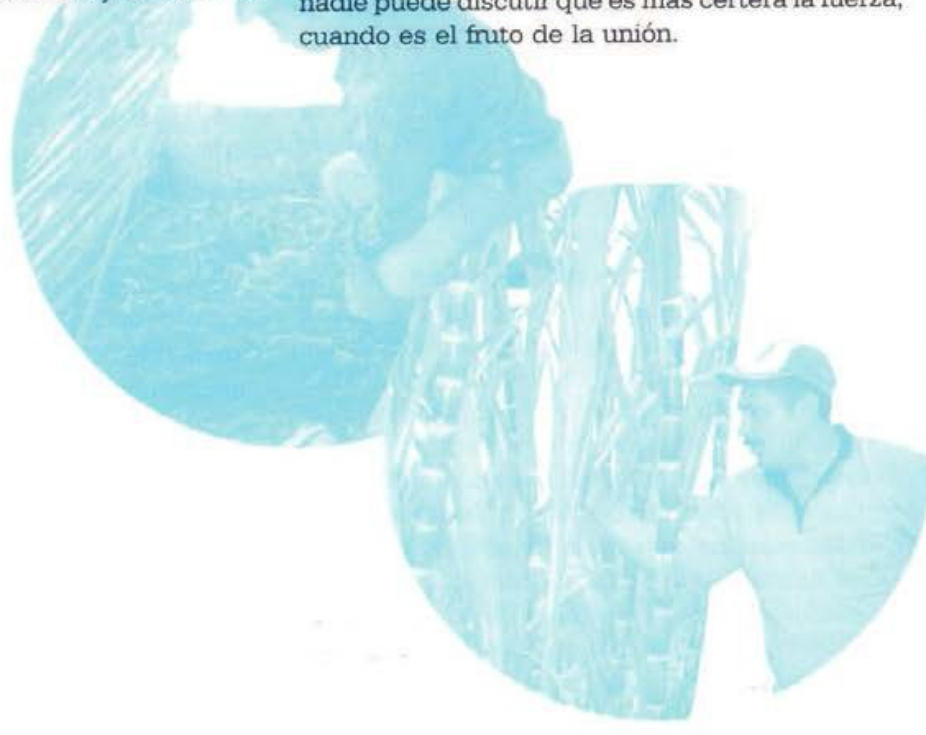

